\section{Life in Science}

\section{Richard Calendar}

Email: rishard@berkeley.edu

\section{Introduction}

In high school biology class I saw a demonstration of digestion of milk by pepsin. The teacher said, "Enzymes cause digestion and this process is called biochemistry. Lots of money is going into biochemistry." This incident settled my career goal. Thus, at Duke University I worked on carbohydrate synthesis in Gene Davidson's lab.

\section{Stanford University}

As a graduate student at Stanford University I worked on E. coli tyrosyl-tRNA synthetase in Paul Berg's lab. I learned that E. coli tyrosyltRNA synthetase can attach D-tyrosine and L-tyrosine to tRNA while a second, editing enzyme, can remove the D-tyrosine. Paul is my favorite scientist, because he has such a creative intelligence and unerring positive attitude. Everytime I get grumpy, I remind myself that Paul would be cheerful. Looking ahead, it seemed to me that protein synthesis would be a difficult field for a young investigator.

The research of Dale Kaiser and Dave Hogness in our department seemed more promising. Dale's lab was studying the elements of lysogenization by temperate phage $\lambda$. Dave was studying the arrangement of genes on $\lambda$ DNA, using shear fragments of the DNA, which enter the cell with the help of infecting $\lambda$. Al Hershey presented a seminar on the discovery of $\lambda$ 's sticky ends, and Dale's lab determined the structure of those sticky ends, using DNA polymerase I and exonuclease III. The work on sticky ends was so striking that it settled my future direction. I had never been to Europe, and I wanted to study phage. Paul suggested Joe Bertani, whom he said was one of the bright, young guys. He had "gone native," that is, to Stockholm. Dale wrote to me from his sabbatical in England to say that there were two Bertani's, Joe and Bettytwo for the price of one-and that Joe was the best teacher among the phage investigators in Europe. A postdoctoral fellow, Georges Balassa, told me that he had visited the Bertani lab and was impressed by a graduate student, Gunnar Lindahl. I was further encouraged to go to Sweden by Ingmar Bergman's movies, which convinced me that Swedes were very interesting, and a Playboy magazine feature, that painted Stockholm as alluring. Gunnar had made a genetic map of phage P2 and found a large blank region. We figured that this hole was the place where P2 DNA integrated into the host chromosome. Doing three-factor crosses, using P1 transduction, we were able to show that this was true in three different chromosomal integration sites. I had hoped to make a physical map of P2 DNA using shear fragments, but $\mathrm{P} 2$ shear fragments were inactive in helper-dependent transformation. While doing this project I noticed that calcium ions stimulated helper-dependent transformation, even up to $0.1 \mathrm{M}$. I could not get helperindependent transfection with P2 DNA, but Mort Mandel got it to work with P2-related phage 186. David Denhart's lab published on mutants of E. coli (rep-) that could not allow replication of minute phage $\phi X-174$. I found that these mutants were also defective for P2 growth. Joe pointed out that Gianpiero Sironi had isolated such a mutant, and he revived it. Gianpiero's mutant had an additional nutritional requirement (ilv), and the rep and ilv mutants turned out to be closely linked. With a mapped gene being required for replication of two entirely different phages, Arthur Kornberg's lab became inspired to show that Rep is a DNA helicase.

\section{UC Berkeley}

When I got to Berkeley, Gianpiero Sironi and Harvey Bialy joined my lab to study why $\lambda$ will not grow on P2 lysogenic strains. They showed that $\lambda$ bio transducing phages, which lack the $\lambda$ recombination genes, grow on $\mathrm{P} 2$-lysogenic strains. This "spi selection," is used to select for $\lambda$ phages into which foreign genes have been cloned. From our biological data, Harvey figured out that the $\lambda$ recombination region must encode an inhibitor of $E$. coli's RecB nuclease. This was the first suggestion that a virus could inhibit a host enzyme, and this proposition was confirmed biochemically in three different labs at Berkeley. Mel Sunshine came to my lab and isolated E. coli mutants that did not allow P2 to grow. I was on sabbatical in Wolfram Zillig's lab in Munich where we showed that one of these mutants contained the first mutation in the $\alpha$ subunit of RNA polymerase. It blocked P2 late gene expression and showed that the $\alpha$ subunit could be involved in the regulation of gene expression. Gail Christie

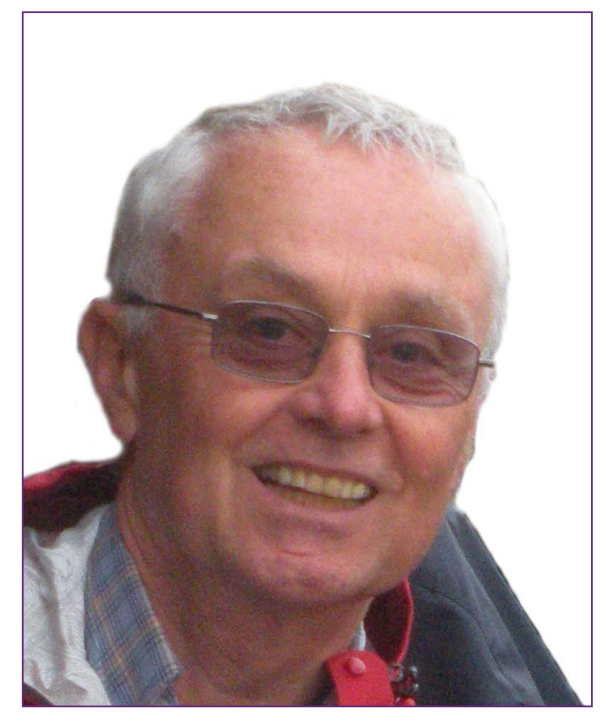

Richard Calendar, Department of Molecular and Cell Biology; College of Letter and Science; University of California, Berkeley; Berkeley, CA USA

brought my lab into the molecular age. She showed that $\mathrm{P} 2$ has a very small peptide that binds to P2 late promoter DNA and to the subunit of RNA polymerase, activating late gene transcription. Conrad Halling dragged me into the bioinformatics field before it was fully formed. He took all of Elisabeth HaggårdLjungquist's P2 DNA sequences, published and unpublished, and compared them with Mu sequences printed in the Mu book. This led him to show that coliphage tail fibers are made of small modules that undergo exchange more rapidly than previously appreciated. This work also led Conrad to propose that the original $\lambda$ phage had side tail fibers. David Ow, who had been an undergraduate researcher in my lab, became an investigator of the US Department of Agriculture. He offered me funding to hire Lynn Thomason to test phage integrases as potential tools for eukaryotic genetics. Maggie Smith had published that Streptomyces phage phiC31 integrase required neither supercoiled DNA nor host proteins. Her system seemed promising. We tested phiC31 integrase in Schizosaccharomyces pombe, and it worked. When Dan Portnoy moved to my department, he asked me to help make an integration vector for Listeria monocytogenes. An integration vector is a plasmid that replicates in $E$. coli but integrates, using a phage integrase, into the Listeria genome. We made such a vector. It allowed us to construct a Listeria strain that can infect mammalian cells, without spreading 
from cell to cell, excreting a cancer cell antigen, and generating an immune response to cancer cells. In the 1970s I was assigned to create the first course in a molecular biology major. There were only two textbooks in the field, both somewhat out of date, so I had to decide what to present and how to organize it. In the middle of my lecture, one student suggested a better organization. Since this student was so bright, I had him work in my laboratory. The first thing that he did was to try to melt a bottle of soft agar directly on a hot plate. It burst. Then I felt that at least I knew something that this clever student did not know. The student was Andy Fire, who went on to win the Nobel Prize for the discovery of interfering RNA. 